\title{
Posterior Foramen Magnum Meningioma
}

National Cancer Institute

\section{Source}

National Cancer Institute. Posterior Foramen Magnum Meningioma. NCI Thesaurus.

Code C5282.

A mening ioma that affects the posterior foramen magnum. 